TI 2017-061/VII

Tinbergen Institute Discussion Paper
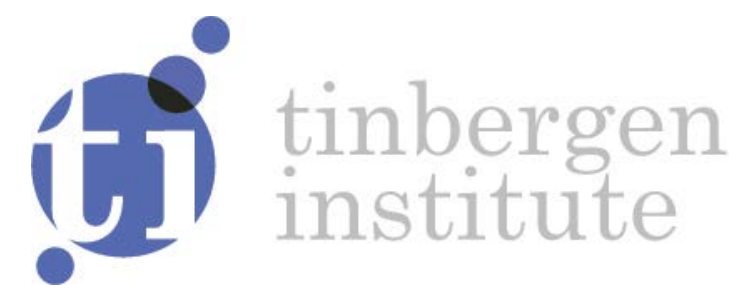

\title{
Increasing the well-being of others on-the-job and outside the workplace
}

Max van Lent ${ }^{1}$

${ }^{1}$ Erasmus University Rotterdam, The Netherlands 
Tinbergen Institute is the graduate school and research institute in economics of Erasmus University Rotterdam, the University of Amsterdam and VU University Amsterdam.

Contact: discussionpapers@tinbergen.nl

More TI discussion papers can be downloaded at http://www.tinbergen.nl

Tinbergen Institute has two locations:

Tinbergen Institute Amsterdam

Gustav Mahlerplein 117

1082 MS Amsterdam

The Netherlands

Tel.: +31(0)205984580

Tinbergen Institute Rotterdam

Burg. Oudlaan 50

3062 PA Rotterdam

The Netherlands

Tel.: +31(0)10408 8900 


\title{
Increasing the well-being of others on-the-job and outside the workplace
}

\author{
Max van Lent*
}

April 20, 2017

\begin{abstract}
We study the relationship between workers' opportunities to help others on-the-job and volunteering behavior outside the workplace. We predict that there is substitutability between workers' contribution to other peoples' well-being by exerting effort on-the-job and outside the workplace. We test this prediction using rich data from the Dutch LISS Panel. We exploit variation in workers' opportunities to help others on-the-job from two sources: i) workers' job switching behavior and ii) changes in workers' opportunities to help others on their current job through plausibly exogenous changes in workers' match of mission preferences with their employer. We find some support for our prediction.
\end{abstract}

Keywords: altruism, charitable donations, volunteering, public sector employment, job switchers, mission motivation.

JEL: D64, H11, J45, M50.

*Department of Economics, Erasmus University Rotterdam, and Tinbergen Institute. E-mail: vanlent@ese.eur.nl 


\section{Introduction}

Recently there has been an increase in the demand for volunteers. For example, the refugee crisis in Europe has let charitable organizations to call for more support in the form of donations and volunteering. ${ }^{1}$ It is important to learn what drives peoples' giving behavior, in order to target and attract volunteers. For instance, is it a good idea to try and recruit people who in their day-to-day work life are involved with helping others, or is it better to focus recruitment resources on people who lack opportunities to help on the job?

In this paper we explore the relationship between workers' opportunities to help others on-the-job and volunteering behavior outside the workplace. Following Dur and Van Lent (2016) we predict that helping people on-the-job and outside the workplace are substitutes. If workers have more opportunities to help others in public sector jobs than in private sector jobs, then workers who switch from the public to the private sector are expected to decrease their contributions to others on-the-job, and hence will by a substitution argument increase their charitable contributions outside work. Workers who switch in the opposite direction are expected to decrease their charitable contributions. To test this prediction we estimate the effect of a change in sector of employment on volunteering using rich data from the Dutch LISS Panel.

The LISS Panel consists of approximately 8,000 individuals and covers the years 2008 to 2016. The questionnaire contains detailed questions on leisure, work, schooling, personality, and politics, which allow us to test our prediction. The key question we use as a proxy for charitable behavior is "Considered all together, how much time do you spend on voluntary work per week, on average".

\footnotetext{
${ }^{1}$ The Red Cross in the UK has e.g. started a project which is intended to attract volunteers especially to offer refugees help during the current refugee crisis in Europe (see: http://www.redcross.org.uk/What-we-do/Refugee-support).
} 
Workers' motivations to switch jobs may not be exogenous to their willingness to volunteer. For example, workers who switch from sector of employment may be different from other workers in many aspects. Therefore in addition to our focus on job switchers, we also analyze a plausibly exogenous change in workers' ability to help others on-the-job, by studying a change in the match of mission preferences of government workers.

Following Zoutenbier (2016), government workers are assumed to have a match in mission preferences when they voted for one of the political parties that is in office. The preferences are classified as a mismatch if the worker has voted for a political party that is not in office. We expect that government workers who have a mission match with their employer feel that they have more opportunities to help others at their work than government workers who do not have a match of mission preferences. Hence, because of a substitution argument, we predict that government workers who share the mission of their employer volunteer less than government workers who do not share the mission. The LISS Panel contains data covering three government coalition periods, and hence we observe two changes in the composition of the parties that are in office. ${ }^{2}$ We are therefore able to rely on within worker variation in mission preferences.

Our main findings are the following. First, workers who switch from sector of employment do not change their time spent on voluntary work significantly, although the coefficients always have the expected sign. That is, workers who switch from a private sector job to a public sector job (insignificantly) decrease their time spent volunteering, while workers who switch in the opposite direction (insignificanty) increase their time spent on voluntary work. Second, we find that government workers who voted for one of the political parties that is in office, and hence are more able to help others onthe-job, decrease their volunteering by 15 minutes per week on average which

\footnotetext{
${ }^{2}$ Note that the Netherlands has a government in office that usually consists of multiple political parties, but an individual can vote for only one political party.
} 
is in line with our prediction.

One obvious reason for people to volunteer is in order to help others. However, there can be other reasons for workers to volunteer. One potentially important alternative motivation to volunteer is to increase job perspectives. For instance, because a worker obtains skills through volunteering that are useful in the labor market, or because volunteering gives the employer a positive signal about the worker's personality, see for example Baert and Vujić (2016). One may expect the benefits of volunteering for career enhancement to be larger in the beginning of a worker's career, since in this phase other signals about the worker's ability and personality are more scarce. Hence, in order to reduce the channel of career concerns as a reason to volunteer, we estimate our specification also for the subsample of more experienced workers (i.e. the workers for whom we expect career perspectives to be less of a reason to volunteer).

Using the subsample of workers that are over 40 years of age we find significant and stronger effects than for the full sample. These experienced workers who switch from the private to the public sector decrease their time spent volunteering by on average 37 minutes per week. Government workers who are over 40 years of age and previously had a match in mission preferences, but after the national election not anymore, increase their time spent volunteering by on average 23 minutes per week.

This paper is most closely related to Dur and Van Lent (2016). Both papers study the relationship between workers' occupational choice, altruistic preferences, and prosocial behavior outside the workplace. However there are also important differences between both papers. The main differences are the following. This paper explores panel data while Dur and Van Lent use cross sectional data. ${ }^{3}$ We study a sample of Dutch workers, while Dur and Van Lent study German workers. Besides analyzing job switchers, this paper

\footnotetext{
${ }^{3}$ One important advantage of panel data is that there is less of a concern for omitted variable bias, since individual fixed effects control for all time invariant factors, observed and unobserved.
} 
also uses a plausibly exogenous change in workers ability to help others onthe-job by studying changes in the match of mission preferences between government workers and their employer. Finally, we have rich data on time spent volunteering, while Dur and Van Lent (2016) have richer data on money donations to charity. Time donations are different from money donations in several respects. On the one hand, donating time is more personal and may therefore be more closely related to helping others on-the-job than to money donations. On the other hand, workers may also choose to volunteer for other reasons than to help other people, for instance in order to increase career perspectives.

Our research is also related to a body of literature that studies the relationship between workers' time use on activities on-the-job and outside the workplace. Examples are the time spent on physically intensive work on-thejob and outside the workplace (see e.g. Tudor-Locke et al. 2011), time spent on work in the household and paid work (see e.g. Krantz-Kent 2009), and the effect of framing compensation schemes on time spent on-the-job and volunteering (see e.g. DeVoe and Pfeffer 2007). These papers generally find that workers' on-the-job behavior affects their behavior outside work. We contribute to this literature by studying the relation between time spent on helping others on-the-job and outside the workplace.

This paper is also related to a body of literature in economics that studies workers' intrinsic motivation in the workplace. Some theory papers have studied workplace behavior of intrinsically motivated workers, see for example Francois (2000, 2007), Besley and Ghatak (2005, 2016), Prendergast (2007), Brekke and Nyborg (2008), and Delfgaauw and Dur (2008, 2010). An increasing number of empirical papers have tested some of these theoretical predictions, see for example Dur and Zoutenbier (2014, 2015), Zoutenbier (2016), and Carpenter and Gong (2016). Our paper contributes to this literature by empirically testing the relation between workers' opportunities to help others on-the-job and volunteering behavior outside the workplace. 
Moreover, there is a literature in public administration that studies whether workers in some sector or jobs are more altruistic than in others. In order to answer this question, researchers often study only peoples charitable behavior outside the workplace, see for example (Brewer 2003, Houston 2006, Rotolo and Wilson 2006, and Lee 2012). Based on our substitution argument, this analysis is flawed and leads to an underestimation of public sector workers' altruistic preferences. For a more extensive discussion of this argument, see Dur and Van Lent (2016).

Finally, this paper is related to a literature that analysis why people with similar characteristics and preferences have different volunteering rates. For example Hackl et al. (2012) study the state's role in influencing workers' decision to volunteer, using data from the European Value Survey and the World Value Survey. They find that volunteering participation rates vary greatly across countries, even after controlling for individual workers' characteristics. The authors explain variation in volunteering by differences in institutional and political factors. We study whether occupational choice leads similar people in terms of preferences to make different volunteering decisions. However we study only workers within one country.

This paper is structured as follows. The next section describes the data and empirical strategy. In the third section we discuss the results, and the fourth and final section contains the conclusion.

\section{Data and Empirical Strategy}

In this paper we use data from the Longitudinal Internet Studies for the Social sciences (LISS) panel. The LISS panel is an unbalanced panel consisting of approximately 8,000 individuals. Participants are selected through random sampling from the population register by Statistics Netherlands. Individuals complete online questionnaires every month, and are paid for each completed questionnaire. The first wave was conducted in 2008 and the most 
recent wave was conducted in 2016. The panel includes modules on Social Integration and Leisure, Work and Schooling, Personality, and Politics and Values. Each of these modules are administered once a year. For our analysis we use data from the years 2008 to 2015 .

The key variables used for this paper are sector of employment and the number of hours spent on voluntary work on average per week. The sector of employment is measured using the question: "In what type of organization do you work?" The organization types the participant could choose from are: "public or semi-public sector" and "private company". The number of hours spent volunteering are measured by the question: "Considered all together, how much time do you spend on voluntary work per week, on average?".

The econometric specification that we use in order to estimate the effect of a change in job type on volunteering reads:

$$
C H_{i, t}=\alpha_{i}+\beta P_{i, t}+\psi X_{i, t}+\tau_{t}+\varepsilon_{i, t}
$$

where $C H_{i, t}$ is charitable behavior outside the job of person $i$ at time period $t ; \alpha_{i}$ is the individual fixed effect; $P_{i, t}$ a dummy variable that equals one if a worker has a public sector job; $X_{i, t}$ is a vector of (time varying) control variables; and $\tau_{t}$ is the time fixed effect. As a measure of charitable giving we use the respondents' average number of hours spent volunteering per week. We estimate time volunteering using Ordinary Least Squares with time and year fixed effects. A disadvantage of using a linear specification for volunteering is that this specification can predict negative values for the number of hours a worker volunteered. Further, this specification does not take into account that many workers spend zero hours per week on average on voluntary work. We have also estimated a fixed effects Poisson specification. A Poisson specification deals in a better way with the large fraction of zeros in the data, and does not allow values to be negative, but a disadvantage of this model is that data should be discrete (i.e. the dependent variable should 
be count). ${ }^{4}$ These results do not differ much from those estimated using OLS and are available upon request. Since we expect that helping others on the job and outside the job are substitutes, we predict that $\beta<0$.

Since switching jobs is endogenous, we also analyze the effect of a plausibly exogenous change in workers' ability to help others on-the-job on charitable behavior outside work. Following Zoutenbier (2016) we use changes in the composition of the political parties that are in office, and workers' political preferences in order to establish workers' mission preferences. For political preferences we used the question: "For which party did you vote in the parliamentary elections of [22 November 2006 / 9 June 2010 / 12 September 2012]?" Participants are considered a match if the political party they voted for in the election is in office in that same time period. When mission preferences match we assume that the ability of government workers to help others is larger than for government workers whose preferences do not match. Note that we focus here on government workers instead of all public sector workers. The reason is that we expect that the effect of the political parties in office on the work that people do is larger for government workers than for other public sector workers.

In order to estimate the effect of a change in mission preferences on charitable behavior (outside the job) we estimate the following equation:

$$
C H_{i, t}=\alpha_{i}+\delta G_{i, t}+\phi M_{i, t}+\gamma\left(G_{i, t} * M_{i, t}\right)+\varphi X_{i, t}+\tau_{t}+\varepsilon_{i, t}
$$

where $G_{i, t}$ is a dummy that equals one if the worker is employed in the government sector and zero if not employed in the government sector; $M_{i, t}$ is a dummy that equals one if the worker has voted for a political party that is in office and zero if the worker voted for another party. We expect that

\footnotetext{
${ }^{4}$ To be more precise, we estimate the Poisson specification with robust standard errors. This relaxes the assumption that the conditional mean should equal the conditional variance.
} 
government workers who voted for one of the political parties that are in office believe they are better able to help others on their job than workers with non-matching preferences. Hence because of the substitution argument we predict that $\gamma<0$.

Table 1 displays the descriptive statistics. Our full sample consists of 21,395 observations of 6,573 individuals, of which $21.3 \%$ spent some time volunteering. On average respondents volunteer 58 minutes per week, and $37.9 \%$ of the respondents is employed in the public sector.

Comparing charitable behavior of workers between sectors, we see that public sector workers on average perform more voluntary work. Further, workers in the public sector are older, have less children, and work less hours. Since the coefficient for the public sector dummy in our specification is identified by those people who switch from the public to the private sector or vice versa, it is interesting to learn how often respondents switch between sectors. Of the 6,573 individuals, 463 switch at least once from sector of employment between 2008 en 2015 (i.e. $7.0 \%$ of the respondents in the sample).

Finally, one worry may be that workers' ability to change their time spent on voluntary work is limited (e.g. because people are habitual or because many volunteering activities require commitment for a long time). From the data we see that in our sample the within-worker variation of time spent volunteering is 2.23 hours, compared to the between-worker variation of 3.94 hours. Hence, although the within-worker variation is less than the between variation we expect that the within-worker variation is enough to be able to expect workers' job choice and behavior to affect volunteering behavior.

\section{Results}

\subsection{Job switchers and charitable behavior}

Table 2 shows the estimation of equation (1) using Ordinary Least Squares with individual and time fixed effects. We cluster standard errors at the 
individual level to correct for correlation of the error term for individuals over time. The first column displays the effect of sector of employment on time spent on voluntary work without control variables. We find that workers who switch from the private to the public (public to the private) sector decrease (increase) their volunteering by 9 minutes on average per week, but this effect is highly insignificant.

In the second column we add job characteristics that vary over time and are expected to be important to control for. ${ }^{5}$ The job characteristics we include are the actual average hours worked per week and the distance from home to work in minutes, since we expect these characteristics to differ over time and have a direct impact on the ability to spend time volunteering. Further, we include income because income can be used to help others by making money donations, which may influence workers willingness to volunteer (see Andreoni et al. 1996, and more recently Feldman 2010). Another reason to include income as a control variable is because paying taxes over one's income can, by some people, also be seen as a donation to society. Finally we include tenure on-the-job, since workers can also switch jobs within sector, and a new work environment in itself can have an effect on volunteering. If we compare the first column of Table 2 with the second, we see that the additional control variables do not change the result much. The coefficient changes from -0.150 to -0.128 and remains highly insignificant. We see that most control variables are individually insignificant, with hours at work as the exception. ${ }^{6}$ The relation between hours at work and volunteering is negative, as expected.

We can also analyze whether job choice has an effect on the decision to volunteer, i.e. the extensive instead of the intensive margin. We estimate a

\footnotetext{
${ }^{5}$ Note that we only need to consider time varying variables as controls, since variables that are time invariant are already taken up by the individual fixed effect, and are thereby already controlled for. Control variables as education or marital status are also not included here, since they hardly vary for the workers in the sample period.

${ }^{6}$ Comparing the model with and without time varying controls we find that the null hypothesis that the coefficients of the added control variables all equal zero is rejected.
} 
Binary Logit specification, with the dependent variable equal to one if the worker has volunteered, and equal to zero if the worker has not volunteered. We find that there is also no significant effect on the extensive margin. The results are available upon request.

Many empirical papers that attempt to compare jobs in which workers have plenty of opportunities to help others with jobs that offer less of these opportunities compare jobs in the public sector with jobs in the private sector. Other papers compare jobs in different industries. Hence, we also estimate equation (1) comparing workers in different industries. We define a public service job (i.e. a job that offers plenty of opportunities to help others) as a job in the Education, Government, Healthcare and Welfare industry, or Environmental Services, and the other job types as regular jobs. ${ }^{7}$ We report the results in Table 3 . The public service dummy is negative as predicted but again highly insignificant.

All the variation in the public sector dummy stems from those workers who switch between sectors. It is not unlikely that workers who switch from the public to the private sector (or vice versa) are inherently different from those workers that do not switch. If this is the case it may be worthwhile to look at those workers who switch from sector of employment at least once during the sample period. In Table 4 we compare the descriptive statistics of the workers who switch at least once, with the workers that never switch. We see that workers who switch at least once volunteer more hours, work less hours, live further away from their job, and have a lower income. Also more workers switch from the public sector to the private sector than vice versa. Since workers that switch from sector of employment are so different from those that do not switch, it may be the case that the difference in charitable behavior for switchers is now partly captured by the control variables. If

\footnotetext{
${ }^{7}$ The remaining industries include: agriculture forestry fishery hunting, mining, industrrial production, utilities production distribution or trade, construction, retail trade, catering, transport storage and communication, financial, business services, environmental services, culture, and other services.
} 
we estimate equation (1) for the sample of job switchers we get qualitatively similar results as for the full sample. The results are available upon request.

Switching sector of employment may be endogenous to charitable giving outside work. Workers for example can decide to switch jobs because they anticipate that they want to help others more in the future. If this, or something else that is directly related to charitable behavior, is the reason for a switch in sector of employment, our results would be biased. ${ }^{8}$ In order to reduce the probability that workers switch for reasons that are related to charitable giving, we ideally want to look at people who have to switch jobs for reasons that are exogenous to volunteering.

In the questionnaire respondents are asked whether and why they are looking for a new job. One possible answer category is that the respondent is looking for a new job because he or she is uncertain whether their current job will continue to exist. Some respondents switched from sector of employment the year after they said that they were looking for a new job because they were uncertain whether their job would continue to exist. For those workers we are more certain that they are not switching jobs because they want to have a better opportunity to help others. Hence we also estimate equation (1) including these workers only. We find no significant effect of a change in sector of employment on charitable behavior. However, a reason for the insignificant coefficient may be that the sample size is too small. ${ }^{9}$

\subsubsection{Stability of altruistic preferences}

In the models we estimated so far we did not include altruism as a control variable. The reason is that in most of the literature altruism is assumed to

\footnotetext{
${ }^{8}$ But there are many other reasons why workers switch jobs that are likely to be more important for many people. Job related reasons to switch jobs are for example the social environment (Abassi and Hollman 2000), job-related stress (Firth et al. 2004), organizational culture (Park and Kim 2009) or compensation schemes. But also family reasons can be a reason to change jobs.

${ }^{9}$ Only 188 people switch the year after they said that there were looking for a new job because they are uncertain whether their current job will exist in the future.
} 
be an individual characteristic that is stable over time. By using individual fixed effects we then automatically control for workers' altruistic preferences. However, it may be the case that workers' altruistic preferences change after they switch from sector of employment. For instance because workers learn in their new public sector job that helping others is much more intrinsically rewarding than they expected and as a consequence they become more willing to help others. Alternatively, workers' altruistic preferences change because their social environment changes (a recent field experiment bij Kosse et al. 2016 finds evidence that social environment has a causal effect on altruistic preferences).

In our data we have two questions that we can use to elicit workers' altruistic preferences, and hence we can test whether altruistic preferences change when workers switch from sector of employment. Participants are asked to describe how accurately each statement describes them: "I feel little concern for others" and "I am not interested in other people's problems". Both questions can be answered on a 5 point scale ranging from "very inaccurate" to "very accurate". We then construct our altruism parameter by taking the average of the answers to the two questions. We subsequently estimate the effect of a change in sector of employment on altruism and do not find any evidence that a change in sector of employment leads to a change in altruistic preferences (see Table A.1).

\subsubsection{Volunteering and career concerns}

One obvious reason for people to volunteer is in order to help others. However, there can be many reasons for people to volunteer. One potentially important alternative motivation for people to volunteer is to increase their career perspectives. For instance, by volunteering one may obtain skills that are relevant for the labor market, or one may be able to signal something about his or her personality that is valued by potential employers. Baert and Vujic (2016) find using a field experiment that volunteering has a pos- 
itive effect on the probability to be invited for a job interview. One may expect that some of the positive effects of volunteering for the labor market are of particular importance at the beginning of one's career. ${ }^{10}$ Therefore, we expect that older workers volunteer less for career enhancement. Hence, in order to be able to better estimate the substitutability between helping others on-the-job and outside the job through volunteering, we next estimate equation (1) for older workers only. To be precise, we estimate equation (1) for workers who are over 40 years old. In Table 5 we report the results of the more experienced workers. We see that more experienced workers who switch to the public sector decrease their time spent volunteering by 37 minutes on average per week. In column two we see that this result is robust for adding the time varying control variables.

\subsubsection{Highly educated job switchers}

Previous research (see e.g. Lewis and Frank 2002 and Dur and Zoutenbier 2014, 2015) has found that more altruistic workers select into public sector jobs, and that these patterns are stronger for the sample of workers that is highly educated. One interpretation of this finding is that in the public sector especially the highly educated are able to help others on-the-job and therefore the selection pattern is stronger for highly educated workers. If the difference in the opportunity to help others on-the-job between the public and private sector is larger for highly educated, then this would, following our substitution argument also imply that the difference in volunteering would be larger. In Table 6 we estimate equation (1) for the subsample of highly educated workers. ${ }^{11}$ We find that the public sector dummy is again negative, but not significantly different from zero.

\footnotetext{
${ }^{10}$ For example, volunteering can provide a signal about the worker's personality. This signal is likely to be more informative in the beginning of the worker's career when information about the worker's personality is more scarce.

${ }^{11}$ We define workers as highly educated if they have either completed a degree in higher vocational training or have (at least) an undergraduate degree at a university.
} 


\subsection{Match of mission preferences and charitable be- havior}

So far we have focused on analyzing the relationship between helping others on-the-job and outside the workplace, using job switchers. Since switching from sector of employment is endogenous, we now provide an alternative for identifying a change in the ability to help others on-the-job by exploiting plausibly exogenous variation in opportunities to help others on the current job.

Zoutenbier (2016) analyzed using the same data (but exploiting a smaller time span), the effect of a (mis)match of mission preferences on job satisfaction for government workers. He defines workers to have a mission match when they voted for a political party that is in office. He then exploits the fact that the composition of the government changes over time, and hence whether government workers have a match with the mission of the government also changes over time. Zoutenbier finds that government workers who voted for a coalition party are more satisfied with the type of work they do.

If we assume that government workers believe they are better able to help others when the organization's preferences are in line with the worker's preferences, we can use changes in the match of mission preferences. Using the substitution argument, we predict that government workers who voted for a political party that is in office, are better able to help others on-the-job and as a consequence they will volunteer less.

In order to test this prediction we estimate equation (2) and report the results of the full sample in Table 7 . In column 1 we see the effect of a match of mission preferences with the coalition of government workers and non-government workers. We see that government workers who voted for one of the political parties that is in office (i.e. workers with a match in mission preferences) volunteer on average 15 minutes less per week. When including the time varying control variables in column 2 , we find that the results hardly change. 
Since in the Netherlands the government in our sample period always consisted of multiple political parties, we estimate a match of mission preferences using alternative definitions for robustness. Following Zoutenbier (2016) we create a dummy that equals one only if the worker voted for the largest political party in government, and we use the workers' stance toward all political parties. By doing this we see that the coefficient of interest oftentimes becomes statistically insignificant.

Using the same arguments as before, we expect the effects to be stronger for more experienced workers (see Table 8) and for highly educated workers (see Table 9). We find that indeed the effects are larger for the sample of workers that is at least 40 years old. To be precise government workers who previously had a match in mission preferences, but after election not anymore, increase their volunteering with on average 23 minutes per week. For the subsample of highly educated workers we find a similar increase in the size of the coefficient, although the coefficient becomes insignificant.

\section{Concluding remarks}

In this paper we studied the relationship between workers' prosocial behavior on-the-job and outside the workplace. We predict that there is substitutability between workers' opportunities to help others on-the-job and volunteering outside the workplace. Using rich panel data from the Longitudinal Internet Studies for the Social Sciences (LISS) we test this prediction in two distinct ways. First, we compare volunteering behavior of workers who switch between public sector and private sector jobs. This stems from the assumption that workers in the public sector often have plenty of opportunity to help others on-the-job, while for workers in the private sector the opportunities to help others are more scarce. Second, we analyze the change in match of mission preferences of government workers on volunteering behavior. Government workers are considered a match if they voted for one of the political 
parties that is in the coalition government. Using the variation in political parties that are in the coalition government over time, government workers switch from a match to a mismatch in preferences and vice versa. We predict that government workers who voted for one of the political parties that is in office, feel that they have plenty of opportunties to help others on-the-job, and hence they will volunteer less.

We find some support for our prediction. We find that workers who switch from a public to a private sector job (or vice versa) do not significantly change their volunteering behavior. However, we do find results that are in line with our prediction when we focus on changes in the match of mission preferences for government workers. We find that government workers with a mission that matches their employer's mission, volunteer on average 15 minutes less per week. Besides volunteering for the purpose of helping others, workers can also volunteer for career concerns. Since we expect the effect of volunteering on career perspectives to be larger for young workers, we also focus on the subsample of older workers. We indeed find stronger effects for older workers, suggesting that some of the young workers volunteer for career enhancement.

The fact that we find that there is some substitutability between opportunities to help other people on-the-job and volunteering implies that job design can lead to crowding out (and crowding in) of charitable behavior. This is something that policy makers and socially responsbile organizations should take into account when designing jobs.

There can be many reasons why we do not find stronger support for our predictions. One reason can be that helping others on-the-job is not a (strong) substitute for volunteering outside the workplace in cases where the beneficiaries of the help on-the-job and outside the job are a very different type or group of people.

In this paper we rely on job switchers in order to estimate the relationship between helping others on-the-job and outside work. There are many reasons for workers to switch jobs, some of them may be directly related to the 
willingness to do good on-the-job, this may bias the results. Hence a cleaner way to estimate the effect of a job switch on workers' willingness to help others outside work, would be if the decision to switch is entirely exogenous to workers' willingness and ability to help others.

The ideal setting to test our hypothesis would therefore be, to have randomly assigned workers change jobs and estimate their charitable behavior before and after the job switch. It is off course very unlikely that such an experiment can take place. A more plausible alternative would be to exploit exogenous variation created from closure of a large workplace. If there would be a firm that is closed and the employer is obliged to find a new employer for its employees, we could test our predictions. We would compare workers' charitable behavior outside the job before and after the plant closure. Also here two issues arise. First, the change in job type or tasks should be large enough (i.e. the difference in opportunities to help others on-the-job should be sufficiently large). Second, workers can still self-select into other jobs instead of working for the proposed new employer. This would again result in a non-random subsample of workers that can be studied. Hence, unless the above issues are properly dealed with, this type of exogeneous variation is not obviously better than our approach. 


\section{References}

[1] Abbasi, S.M., \& Hollman, K. W. (2000). Turnover: The real bottom line. Public Personnel Management, 29(3), 333-342.

[2] Andreoni, J., Gale, W.G., Scholz, J.K., \& Straub, J. (1996). Charitable contributions of time and money. University of Wisconsin-Madison Working Paper.

[3] Baert, S., \& Vujić, S. (2016). Does It Pay to Care? Prosocial Engagement and Employment Opportunities. IZA Discussion Paper No. 9649.

[4] Besley, T., \& Ghatak, M. (2005), Competition and Incentives with Motivated Agents, American Economic Review, 95(3): 616-636.

[5] Besley, T., \& Ghatak, M. (2016). Market Incentives and the Evolution of Intrinsic Motivation. Working paper London School of Economics.

[6] Brekke, K. A., \& Nyborg, K. (2008). Attracting responsible employees: Green production as labor market screening. Resource and Energy Economics, 30(4), 509-526.

[7] Brewer, G. A. (2003). Building social capital: Civic attitudes and behavior of public servants. Journal of Public Administration Research and Theory, 13(1), 5-26.

[8] Carpenter, J., \& Gong, E. (2016). Motivating Agents: How much does the mission matter?. Journal of Labor Economics, 34(1), 211-236.

[9] Clary, E.G., Snyder, M., \& Stukas, A.A. (1996). Volunteers' motivations: Findings from a national survey. Nonprofit and Voluntary Sector Quarterly, 25(4), 485-505.

[10] Clary, E.G., \& Snyder, M. (1999). The motivations to volunteer theoretical and practical considerations. Current directions in psychological science, 8(5), 156-159. 
[11] Delfgaauw, J., \& Dur, R. (2008). Incentives and Workers' Motivation in the Public Sector. Economic Journal, 118(525), 171-191.

[12] Delfgaauw, J., \& Dur, R. (2010). Managerial talent, motivation, and selfselection into public management. Journal of Public Economics, 94(9), 654-660.

[13] DeVoe, S.E., \& Pfeffer, J. (2007). Hourly payment and volunteering: The effect of organizational practices on decisions about time use. Academy of Management Journal, 50(4), 783-798.

[14] Dur, R., \& van Lent, M. (2016). Serving the Public Interest in Several Ways: Theory and Empirics. Working Paper.

[15] Dur, R., \& Zoutenbier, R. (2014). Working for a good cause. Public Administration Review, 74(2), 144-155.

[16] Dur, R., \& Zoutenbier, R. (2015). Intrinsic motivations of public sector employees: Evidence for Germany. German Economic Review, 16(3), 343-366.

[17] Feldman, N. E. (2010). Time is money: Choosing between charitable activities. American Economic Journal: Economic Policy, 2(1), 103130.

[18] Firth, L., Mellor, D.J., Moore, K.A., \& Loquet, C. (2004). How can managers reduce employee intention to quit? Journal of managerial psychology, 19(2), 170-187.

[19] Francois, P. (2000). 'Public service motivation'as an argument for government provision. Journal of Public Economics, 78(3), 275-299.

[20] Francois, P. (2007), Making a Difference, RAND Journal of Economics, 38(3): 714-732. 
[21] Hackl, F., Halla, M., \& Pruckner, G.J. (2012). Volunteering and the State. Public Choice, 151(3-4), 465-495.

[22] Houston, D. J. (2006). "Walking the walk" of public service motivation: Public employees and charitable gifts of time, blood, and money. Journal of Public Administration Research and Theory, 16(1), 67-86.

[23] Kosse, F., Deckers, T., Schildberg-Hörisch, H., \& Falk, A. (2016). The Formation of Prosociality: Causal Evidence on the Role of Social Environment.

[24] Krantz-Kent, R. (2009). Measuring time spent in unpaid household work: results from the American Time Use Survey. Monthly Lab. Rev., $132,46$.

[25] Lee, Y. J. (2012). Behavioral implications of public service motivation: Volunteering by public and nonprofit employees. The American Review of Public Administration, 42(1), 104-121.

[26] Park, J., \& Kim, T. (2009). Do types of organizational culture matter in nurse job satisfaction and turnover intention?. Leadership in Health Services, 22(1), 20-38.

[27] Prendergast, C. (2007). The motivation and bias of bureaucrats. The American Economic Review, 180-196.

[28] Rotolo, T., \& Wilson, J. (2006). Employment sector and volunteering: The contribution of nonprofit and public sector workers to the volunteer labor force. The Sociological Quarterly, 47(1), 21-40.

[29] Tudor-Locke, C., Leonardi, C., Johnson, W. D., \& Katzmarzyk, P. T. (2011). Time spent in physical activity and sedentary behaviors on the working day: the American time use survey. Journal of Occupational and Environmental Medicine, 53(12), 1382-1387. 
[30] Zoutenbier, R. (2016). The impact of matching mission preferences on well-being at work. Economics of Governance, 17(3), 295-315. 


\section{Tables and Figures}

Table 1: Descriptive Statistics

\begin{tabular}{llll}
\hline & Total & Public (37.9\%) & Private(62.1\%) \\
\hline Volunteering: mean & 0.97 & 1.11 & 0.89 \\
standard deviation & 3.78 & 4.30 & 3.43 \\
Volunteering: \% & $21.3 \%$ & $23.8 \%$ & $19.8 \%$ \\
Age: mean & & & \\
standard deviation & 43.00 & 44.97 & 41.80 \\
& 12.05 & 11.61 & 12.16 \\
Number of children: mean & 1.06 & 1.01 & 1.09 \\
standard deviation & 1.14 & 1.15 & 1.14 \\
& & & \\
Net income: mean & 1723.85 & 1750.21 & 1707.76 \\
standard deviation & 3362.78 & 2987.31 & 3572.66 \\
& & & \\
Hours at work: mean & 30.22 & 29.20 & 30.85 \\
standard deviation & 14.52 & 13.15 & 15.25 \\
& & & 26.14 \\
Distance: mean & 26.57 & 27.27 & 22.41 \\
standard deviation & 22.03 & 21.39 & 9.84 \\
Tenure: mean & 11.36 & 13.48 & \\
standard deviation & 6573 & 11.15 & 8110 \\
\hline Observations & & 2483 & \\
Number of individuals & & & \\
\hline
\end{tabular}


Table 2: Fixed effects Ordinary Least Squares

\begin{tabular}{lcc} 
Dependent variable: Volunteering & \\
\hline Public sector & -0.150 & -0.128 \\
& $(0.215)$ & $(0.212)$ \\
Hours at work & $-0.005^{* *}$ \\
& & $(0.002)$ \\
Net income & -0.000 \\
& & $(0.000)$ \\
Distance & -0.003 \\
& & $(0.004)$ \\
Tenure & -0.011 \\
& & $(0.008)$ \\
Individual and time fixed effects & YES & YES \\
\hline Observations & 21395 & 21395 \\
Number of individuals & 6573 & 6573 \\
\hline Standard errors in parenthese, ${ }^{* * *} \mathrm{p}<0.01, * * \mathrm{p}<0.05, * \mathrm{p}<0.10$. \\
Standard errors are clustered on the individual level.
\end{tabular}


Table 3: Fixed effects Ordinary Least Squares

\begin{tabular}{|c|c|c|}
\hline \multicolumn{3}{|c|}{ Dependent variable: Volunteering } \\
\hline Public service & -0.099 & -0.085 \\
\hline & $(0.233)$ & $(0.229)$ \\
\hline \multirow[t]{2}{*}{ Hours at work } & & $-0.004^{*}$ \\
\hline & & $(0.002)$ \\
\hline \multirow[t]{2}{*}{ Net income } & & -0.000 \\
\hline & & $(0.000)$ \\
\hline \multirow[t]{2}{*}{ Distance } & & -0.004 \\
\hline & & $(0.003)$ \\
\hline \multirow[t]{2}{*}{ Tenure } & & -0.009 \\
\hline & & $(0.006)$ \\
\hline Individual and time fixed effects & YES & YES \\
\hline Observations & 22896 & 22896 \\
\hline Number of individuals & 7027 & 7027 \\
\hline
\end{tabular}


Table 4: Descriptive Statistics

\begin{tabular}{lll}
\hline & Total & Switchers (7.0\%) \\
\hline Volunteering: mean & 0.97 & 1.19 \\
standard deviation & 3.78 & 3.90 \\
Volunteering: \% & $21.3 \%$ & $22.2 \%$ \\
Age: mean & & \\
standard deviation & 43.00 & 38.05 \\
& 12.05 & 13.33 \\
Number of children: mean & 1.06 & 1.07 \\
standard deviation & 1.14 & 1.19 \\
& & \\
Net income: mean & 1723.85 & 1388.26 \\
standard deviation & 3362.78 & 1032.66 \\
& & \\
Hours at work: mean & 30.22 & 27.32 \\
standard deviation & 14.52 & 14.19 \\
& & \\
Distance: mean & 26.57 & 28.25 \\
standard deviation & 22.03 & 22.89 \\
Tenure: mean & 11.36 & 5.85 \\
standard deviation & 10.49 & 1735 \\
\hline Observations & 21395 & 463 \\
Number of individuals & 6573 & \\
\hline
\end{tabular}


Table 5: Fixed effects Ordinary Least Squares, sample: age $>40$ Dependent variable: Volunteering

\begin{tabular}{lll}
\hline Public sector & $-0.611^{*}$ & $-0.620^{*}$ \\
& $(0.326)$ & $(0.324)$ \\
Hours at work & & $-0.009^{* *}$ \\
& & $(0.004)$ \\
Net income & -0.000 \\
& $(0.000)$ \\
Distance & & -0.002 \\
& & $(0.006)$ \\
Tenure & & $-0.016^{*}$ \\
& & $(0.009)$ \\
Individual and time fixed effects & YES & 12541 \\
\hline Observations & 12541 & 3606 \\
Number of individuals & 3606 & YES \\
\hline Standard errors in parenthese, ${ }^{* * *} \mathrm{p}<0.01, * * \mathrm{p}<0.05,{ }^{*} \mathrm{p}<0.10$. \\
Standard errors are clustered on the individual level.
\end{tabular}


Table 6: Fixed effects Ordinary Least Squares, sample: Highly educated Dependent variable: Volunteering

\begin{tabular}{lll} 
Public sector & -0.055 & -0.036 \\
& $(0.324)$ & $(0.328)$ \\
Hours at work & & 0.000 \\
& $(0.003)$ \\
Net income & 0.000 \\
& $(0.000)$ \\
Distance & -0.004 \\
& & $(0.003)$ \\
Tenure & & 0.001 \\
& & $(0.013)$ \\
Individual and time fixed effects & YES & YES \\
\hline Observations & 6878 & 6878 \\
Number of individuals & 2316 & 2316 \\
\hline Standard errors in parenthese, ${ }^{* * *} \mathrm{p}<0.01, * * \mathrm{p}<0.05, * \mathrm{p}<0.10$.
\end{tabular}

Standard errors are clustered on the individual level. 
Table 7: Fixed effects Ordinary Least Squares

\begin{tabular}{|c|c|c|}
\hline \multicolumn{3}{|c|}{ Dependent variable: Volunteering } \\
\hline \multirow[t]{2}{*}{ Government } & 0.209 & 0.218 \\
\hline & $(0.262)$ & $(0.267)$ \\
\hline \multirow[t]{2}{*}{ Match } & 0.079 & 0.077 \\
\hline & $(0.070)$ & $(0.070)$ \\
\hline \multirow[t]{2}{*}{ Government*Match } & $-0.249^{*}$ & $-0.247^{*}$ \\
\hline & $(0.136)$ & $(0.136)$ \\
\hline \multirow[t]{2}{*}{ Hours at work } & & $-0.005^{* *}$ \\
\hline & & $(0.002)$ \\
\hline \multirow[t]{2}{*}{ Net income } & & -0.000 \\
\hline & & $(0.000)$ \\
\hline \multirow[t]{2}{*}{ Distance } & & -0.002 \\
\hline & & $(0.004)$ \\
\hline \multirow[t]{2}{*}{ Tenure } & & -0.008 \\
\hline & & $(0.008)$ \\
\hline Individual and time fixed effects & YES & YES \\
\hline Observations & 16504 & 16504 \\
\hline Number of individuals & 5382 & 5382 \\
\hline
\end{tabular}


Table 8: Fixed effects Ordinary Least Squares, sample: age $>40$ Dependent variable: Volunteering

\begin{tabular}{lll}
\hline Government & 0.037 & 0.033 \\
Match & $(0.502)$ & $(0.511)$ \\
& 0.101 & 0.100 \\
Government*Match & $(0.096)$ & $(0.095)$ \\
& $-0.381^{* *}$ & $-0.382^{* *}$ \\
Hours at work & $(0.172)$ & $(0.173)$ \\
& & $-0.006^{*}$ \\
Net income & & $(0.003)$ \\
& & -0.000 \\
Distance & & $(0.000)$ \\
& & -0.003 \\
Tenure & & $(0.007)$ \\
& & -0.010 \\
Individual and time fixed effects & YES & $(0.009)$ \\
\hline Observations & 10752 & YES \\
Number of individuals & 3331 & 3331 \\
\hline Standard errors in parenthese, $* * *$ & $\mathrm{p}<0.01, * * \mathrm{p}<0.05, * \mathrm{p}<0.10$. \\
Standard errors are clustered on the individual level.
\end{tabular}


Table 9: Fixed effects Ordinary Least Squares, sample: Highly educated Dependent variable: Volunteering

\begin{tabular}{lll}
\hline Government & 0.564 & 0.570 \\
Match & $(0.444)$ & $(0.441)$ \\
& 0.119 & 0.119 \\
Government*Match & $(0.110)$ & $(0.110)$ \\
& -0.377 & -0.379 \\
Hours at work & $(0.235)$ & $(0.235)$ \\
& & -0.002 \\
Net income & & $(0.004)$ \\
& & 0.000 \\
Distance & & $(0.000)$ \\
& & -0.003 \\
Tenure & & $(0.003)$ \\
& & -0.004 \\
Individual and time fixed effects & $\mathrm{YES}$ & $(0.011)$ \\
\hline Observations & 6235 & $\mathrm{YES}$ \\
Number of individuals & 2133 & 2133 \\
\hline Standard errors in parenthese, $* * * \mathrm{p}<0.01, * * \mathrm{p}<0.05, * \mathrm{p}<0.10$.
\end{tabular}

Standard errors are clustered on the individual level. 


\section{Appendix}

Table A.1: Fixed effects Ordinary Least Squares

Dependent variable: Altruistic preferences

$\begin{array}{lll}\text { Public sector } & -0.039 & -0.043\end{array}$

$(0.047) \quad(0.047)$

Hours at work $\quad 0.001$

$(0.001)$

Net income

0.000

$(0.000)$

Distance

0.000

$(0.001)$

Tenure

$-0.001$

$(0.002)$

\begin{tabular}{llc} 
Individual and time fixed effects & YES & YES \\
\hline Observations & 14305 & 14305 \\
Number of individuals & 5931 & 5931 \\
\hline Standard errors in parenthese, ${ }^{* * *} \mathrm{p}<0.01,{ }^{* *} \mathrm{p}<0.05,{ }^{*} \mathrm{p}<0.10$.
\end{tabular}

Standard errors are clustered on the individual level. 